\title{
Enhancing Patient Safety and Access to Care to Populations at Risk of Exclusion: The Example of the Portuguese-Speaking Migrant Community in South London
}

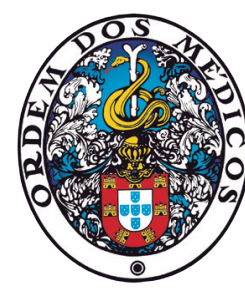

\section{Estratégias para Melhorar a Segurança e Acesso aos Cuidados de Saúde a Populações em Risco de Exclusão: O Exemplo da Comunidade Migrante de Língua Portuguesa no Sul de Londres}

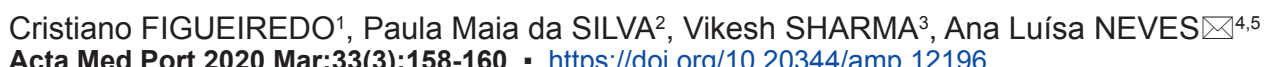

Keywords: Delivery of Health Care; Healthcare Disparities; Social Determinants of Health; Transients and Migrants; United Kingdom Palavras-chave: Assistência à Saúde; Determinantes Sociais da Saúde; Disparidades em Assistência à Saúde; Migrantes; Reino Unido

In Portugal, patients experienced an overall improvement in primary healthcare access in the last few years, with a marked increase in the number of patients with a named family doctor (93\% in 2017 vs $86 \%$ in 2010). ${ }^{1}$ However, Portuguese migrants (and, as a broader community, Portuguese-speaking patients) often experience discrepancies in access to healthcare services. ${ }^{2}$ The main drivers for this inequity are related to living conditions, work, risk behaviours, environmental, and social context. ${ }^{2}$ In the light of the above, how do Portuguese-speaking patients cope from moving from their 'safe environment' - a healthcare system whose stakeholders, principles, rules, and language they fully understand - into a new, unknown system?

We are living in an era where international migration is increasing globally. ${ }^{3}$ In 2017 , it was estimated that there were around 258 million international migrants. ${ }^{3}$ In the United Kingdom (UK), according to the last census, ${ }^{4}$ Portuguese-born citizens represent $23 \%$ of the total volume of migrants. However, establishing the actual size of the Portuguese-speaking community is not straightforward. Many people are not registered or do not answer the census - furthermore, freedom of movement within the European Union makes it very difficult to develop accurate figures. The migrant status is currently recognised as a key determinant of health, as migrants often face unique obstacles in accessing health care, including lack of knowledge about the system and their legal rights, as well as restricted legal entitlements, administrative difficulties, and language barriers. ${ }^{5}$ It is also widely recognised that minority ethnic groups, due to a complex mixture of factors including economic migration, employment, access to housing and education, and cultural understanding are at greater risk of health inequalities leading to poorer outcomes. ${ }^{6}$

Located in South London, Lambeth is a council where many of these difficulties are exposed. It is one of the most populated places in the UK, with a complex social and ethnic mix where over $40 \%$ of residents were born outside the UK. ${ }^{7}$ Importantly, Lambeth has one of the UK's largest Portuguese-speaking communities. Despite the limitation to calculate accurate numbers, it has been estimated that there are around 30000 - 35000 Portuguese native speakers living in Lambeth. ${ }^{8}$ Portuguese-speaking migrants arrived in three waves: 1960s - 1980s (initially concentrated in west London, the generation that established the grouping of shops and businesses known as Little Portugal in Stockwell); late 1990s and early 2000s (a wave of migrants that tended to be from poorer parts of Portugal, to be more transient and less likely to have a good level of English); 2008-onwards (migration of skilled young graduates, sparked by the global economic crisis which led to soaring youth unemployment rates). ${ }^{8}$

The majority of the migrants are from Portugal, but there are also minorities from former colonies including Brazil, East Timor, Angola, Cape Verde, Guinea-Bissau, Mozambique and Sao Tome and Principe. ${ }^{9}$ This community has a strong presence both in terms of numbers and its cultural significance. From a health care and public health perspective, this community presents a high prevalence of longand medium term- chronic conditions, mental health issues, alcoholism, domestic violence and depression. ${ }^{9}$

1. Unidade de Saúde Familiar da Baixa. Agrupamentos de Centro de Saúde Lisboa Central. Lisboa. Portugal.

2. Unidade de Cuidados de Saúde Primários Olivais. Agrupamentos de Centro de Saúde Lisboa Central. Lisboa. Portugal.

3. The Grantham Practice. London. United Kingdom.

4. Department of Community Medicine, Information and Health Decision Sciences (MEDCIDS). Center for Health Technology and Services Research (CINTESIS). University of Porto. Porto. Portugal.

5. Institute of Global Health Innovation. Imperial College London. London. United Kingdom.

$\triangle$ Autor correspondente: Ana Luísa Neves. ana.luisa.neves14@imperial.ac.uk

Recebido: 15 de abril de 2019 - Aceite: 07 de janeiro de 2020 | Copyright @ Ordem dos Médicos 2020 
Importantly, language remains a critical issue for the Portuguese-speaking community, as it is shown in a Portuguese Speaking Community in Lambeth Needs Analysis, ${ }^{9}$ where $81 \%$ of respondents require support with English; 49\% rate as poor their verbal English and 64\% their written English and only $7 \%$ rate themselves as fluent in verbal and written English. ${ }^{9}$ Consequently, there is a lack of understanding in the community of services available in the National Health System (NHS) and an over reliance on private clinics.

\section{A pilot initiative to understand the needs of a migrant community engaging with healthcare}

These concerns about the Portuguese Community in Lambeth inspired an informal partnership between primary care doctors from the UK and Portugal, as well as community members. We approached community members and used focus groups (three focus groups, $n=26$, age 25 - 74 years old, $46 \%$ female, all Portuguese native speakers) to identify the barriers that hinder the use of healthcare services by the Portuguese-speaking migrants. Thematic analysis was used to analyse the information collected. Several participants reported little understanding or usage of services available in the NHS, other than the GP or secondary care, with very little usage of out of hours services. Conversely, community members report to prefer to use private Portuguese clinics, where they can speak their own language, or even travelling back to Portugal for health issues.

We further explored the reasons for this to happen, and six main reasons emerged. The main was the language barrier: "I wish there were more translators in GP surgeries (...) sometimes I receive letters and as I don't understand English I won't do the exams recommended in these letters"; "I would like to have more Portuguese translators in more places as we need that so much". Other reasons included 1) lack of information about the healthcare system; 2) lack of capacity to access and effectively use health-related information (health illiteracy), 3) difficulties registering in a GP surgery, 4) lack of proactivity engaging with healthcare, and 5) mismatched expectations about the NHS and the characteristics of services provided.

\section{Lessons learned and the way forward}

To enhance the understanding of the NHS system, improve confidence in registering with GP, boost usage of other community health care providers including pharmacy, and reduce inappropriate use of emergency departments, we created a welcome pack (available for download at https://lpwp.org/resources/) consisting of an educational leaflet and a Transfer of Care document, both written in Portuguese. The educational leaflet (Fig. 1) is an easy-to-read guide that was distributed in various care providers in Lambeth, community centres, venues, and in the Portuguese Embassy. The leaflet provides information about NHS services (GPs, community services, pharmacy services), how to register with a GP, the screening services available, what to do when a GP surgery is closed, what to do in case of

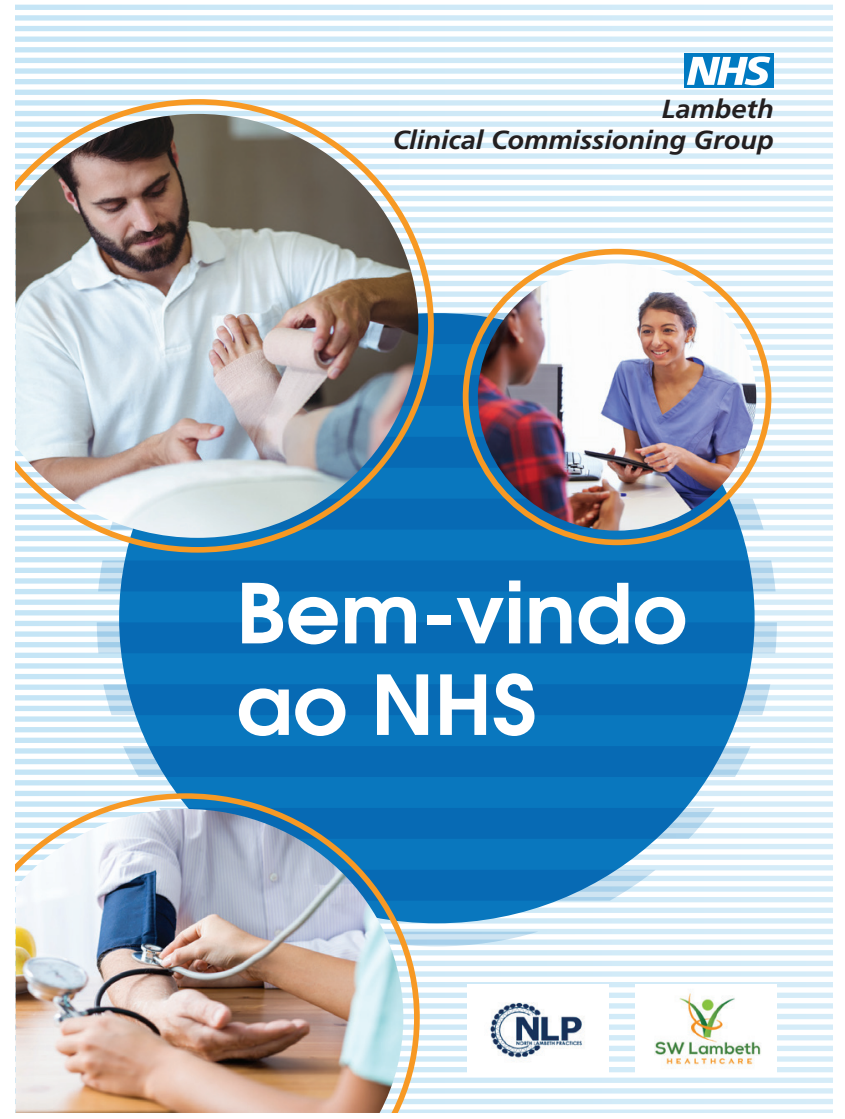

Figure 1 - NHS Welcome Pack

(available for download at https://lpwp.org/resources/)

emergency, as well as relevant contacts. The Transfer of Care document is a document that allows patients to write all their health issues in Portuguese and translate them side-by-side to English (by someone proficient in both languages - either a relative, friend, or staff of a community organisation).

Could this educational leaflet be used to educate patients on the services provided? Could it promote a better use of these services by a migrant community, thus improving health equity? According to our preliminary community survey $(n=24)$, users found the leaflet useful $(92 \%)$ - they would use it as educational material $(91 \%)$ and would advise it to friends or family (100\%). Importantly, they acknowledged having learned new information on 1) how to register with a GP $(75 \%), 2)$ the services available at the GP practice $(75 \%)$, and 3 ) preventive services available (33\%). However, only $50 \%$ considered that this new information would change the way they use the services.

In tightly woven communities such as the Portuguese-speaking community in South Lambeth, observing and imitating peers can have a significant effect on acquiring and changing behaviors. By capitalising on that potential, we are now formally developing an innovative model of community working (Lambeth Portuguese Wellbeing Partnership - www.lpwp.org) that aims to involve community members and leaders, voluntary and community sector organisations as active stakeholders, scoping their perspectives and enrolling them in developing strategies to improve 
their engagement with healthcare services. By enrolling active players in the design of their solutions, they are already taking the first active step to create a step-change in the health and wellbeing of Lambeth residents, and committing to an active role on reducing healthcare inequities in the Portuguese-speaking community. Although designed to answer the needs of the Portuguese-speaking community, this model can be applied to other migrant communities, by connecting them with language-specific resources and

\section{REFERENCES}

1. Ministério da Saúde. Relatório Anual - Acesso a Cuidados de Saúde nos Estabelecimentos do SNS e Entidades Convencionadas em 2017. Lisboa: MS; 2017.

2. Organisation for Economic Co-operation and Development/European Union. Health at a glance: Europe 2018 - State of Health in the EU Cycle. Paris: OECD; 2018.

3. Department of Economic and Social Affairs. Population Division (2017). International Migration Report. New York: United Nations; 2017.

4. Office for National Statistics. UK Census 2011. Newport: ONS; 2011.

5. WHO Regional Office for Europe. Health of refugees and migrants Regional situation analysis, practices, experiences, lessons learned and ways forward. København: WHO; 2018.

6. Barry AM, Yuill C. Understanding the sociology of health: an introduction. London: Sage; 2011. organisations, and work together towards a more holistic and patient-centred model of care.

\section{FUNDING SOURCES}

Ana Luísa Neves is funded by the National Institute for Health Research Imperial Patient Safety Translational Research Centre, with infrastructure support provided by the National Institute for Health Research Imperial Biomedical Research Centre.
7. Lambeth Town Hall. State of the Borough 2014. [accessed 2019 Apr 15] Available in: http://www.lambeth.gov.uk/sites/default/files/ec-lambethcouncil-state-of-the-borough-2014_0.pdf.

8. Melo Nogueira MJ, Porteous D, Guerreiro S. The Portuguese-speaking community in Lambeth: a scoping study. Project Report. London; London Community Foundation; 2015.

9. The Portuguese Speaking Community in Lambeth. Needs Analysis 2011. [accessed 2019 Apr 15]. Available in: http://www.stockwell.org.uk/ wp-content/uploads/2012/03/The-Portuguese-Speaking-Community-inLambeth-Needs-Analysis-2011.doc.

10. Mackay A, Ashworth M, White $P$. The role of spoken language in cardiovascular health inequalities: a cross-sectional study of people with non-English language preference. BJGP Open. 2017;1:bjgpopen17X101241. 